\title{
Quantitative Analysis of Efficiency Improvement of a Propulsion Drive by Using SiC Devices: A Case of Study
}

\author{
Kundan Kumar, ${ }^{1}$ Manuele Bertoluzzo, ${ }^{2}$ Giuseppe Buja, ${ }^{2}$ and Fernando Ortenzi ${ }^{3}$ \\ ${ }^{1}$ Department of Electrical Engineering, Bengal College of Engineering \& Technology, Bidhannagar, Durgapur 713212, India \\ ${ }^{2}$ Department of Industrial Engineering, University of Padova, Via Gradenigo 6a, 35131 Padova, Italy \\ ${ }^{3}$ ENEA-Italian Agency for New Technologies, Energy and Sustainable Economic Development, DTE-PCU-STMA Laboratory, \\ Casaccia Research Center, Via Anguillarese 301, S.M. Galeria, 00123 Roma, Italy
}

Correspondence should be addressed to Manuele Bertoluzzo; manuele.bertoluzzo@unipd.it

Received 21 October 2016; Revised 20 January 2017; Accepted 2 February 2017; Published 28 February 2017

Academic Editor: Changming Liaw

Copyright (C) 2017 Kundan Kumar et al. This is an open access article distributed under the Creative Commons Attribution License, which permits unrestricted use, distribution, and reproduction in any medium, provided the original work is properly cited.

\begin{abstract}
One of the emerging research topics in the propulsion drive of the electric vehicles is the improvement in the efficiency of its component parts, namely, the propulsion motor and the associated inverter. This paper is focused on the efficiency of the inverter and analyzes the improvement that follows from the replacement of the silicon ( $\mathrm{Si}$ ) IGBT devices with silicon carbide (SiC) MOSFETs. To this end, the paper starts by deriving the voltage-current solicitations of the inverter over the working torquespeed plane of the propulsion motor. Then, a proper model of the power losses in the inverter over a supply period of the motor is formulated for the two types of device, including the integrated freewheeling diode. By putting together the voltage-current solicitations and the device power losses, the efficiency maps of the Si IGBT and SiC MOSFET inverters are calculated and compared over the torque-speed plane. The results for the Si IGBT inverter are supported by measurements executed on a marketed C-segment compact electric car, while the SiC MOSFET loss model is validated by an on-purpose built test bench. Finally, the overall efficiency of the propulsion drive is calculated by accounting for the motor efficiency. Main outcomes of the paper is a quantitative evaluation of both the improvement in the efficiency achievable with the SiC MOSFETs and the ensuing increase in the electric car range.
\end{abstract}

\section{Introduction}

It is well known that the main drawbacks of today's electric vehicles (EVs) are the limited range and the long recharging time of the batteries. Thus, it follows naturally to make the best usage of the energy stored in the on-board EV battery pack. A way to reach this objective is improving the efficiency of the propulsion drive, in particular of its two key component parts: inverter and motor, since much of the energy consumed by EVs flows through them [1-4].

Recent advancements in wide bandgap (WBG) devices fabrication, especially for the silicon carbide ( $\mathrm{SiC}$ ) devices, have led to the development of high-voltage power transistors with short switching time and low conduction resistance [5, 6]. Consequently, appreciable improvement in the propulsion inverter efficiency is expected if built up with $\mathrm{SiC}$ devices, such as the SiC MOSFETs, instead of with silicon (Si) IGBTs, owing to the reduction of both switching and conduction losses [7-11].

Most of the existing literature deals with propulsion inverters that utilize Si IGBTs. Recently, a few papers have investigated the efficiency of SiC MOSFET inverters [12, 13]. By expanding their investigation, this paper provides the efficiency map of a SiC MOSFET inverter over the working torque-speed plane of a propulsion motor. For the latter one, a permanent magnet synchronous motor is selected because of its large use in today's EVs. The same investigation is accomplished for a Si IGBT inverter for comparison purposes. The efficiency is calculated in two steps: by deriving the amplitude of the inverter current-voltage solicitations for given values of motor torque and speed and by arranging a suitable model for the losses in Si IGBTs, SiC MOSFETs, and freewheeling diodes. Calculation of the efficiency maps of the 
two types of inverter as well as their comparison has been carried out in the MATLAB environment.

In detail, the paper is organized as follows. Section 2 shortly goes through the $\mathrm{SiC}$ devices. Section 3 derives the expressions of the inverter current-voltage solicitations over the working torque-speed plane of the propulsion motor. Section 4 formulates the loss models for Si IGBTs, SiC MOSFETs, and freewheeling diodes over a supply period of the motor. Section 5 introduces a study case, represented by a marketed C-segment compact car, and gives the characteristics of its battery pack and propulsion motor. Section 6 calculates the efficiency maps of the Si IGBT and SiC MOSFET inverters; then it goes up to the efficiency of the propulsion drives and estimates the range extension attained with the $\mathrm{SiC}$ MOSFET inverter. Section 7 analyzes the effect of a higher junction temperature on the efficiency of the propulsion drive. Section 8 supports the efficiency map calculated for the propulsion drive with the Si IGBT inverter by experimental data. Section 9 concludes the paper. Appendix describes the experimental activities performed to validate the loss model of the SiC MOSFETs.

\section{SiC Devices}

Devices based on WBG semiconductors, in particular on $\mathrm{SiC}$, went through tremendous progress in the last years. They are promising very much in reducing the losses of the power converters and shrinking their dimensions. Indeed, the high breakdown electric field of the $\mathrm{SiC}$ devices allows for thinner and highly doped depletion layer, which reduces their on-state resistance. Besides, the high saturation velocity of the free charges in the $\mathrm{SiC}$ devices allows for a short recombination time, which promotes a significant increase in their switching frequency. Moreover, $\mathrm{SiC}$ can operate at higher junction temperatures than $\mathrm{Si}$ and has higher thermal conductivity and lower coefficient of thermal expansion so that packaging of the $\mathrm{SiC}$ power devices is reliable over a wide temperature range. Furthermore, in recent times, the price of the $\mathrm{SiC}$ devices has dropped markedly so that they are more and more competitive with respect to the conventional Si devices. A cross examination of the main characteristics of $\mathrm{Si}$ and $\mathrm{SiC}$ devices is reported in [5-11].

\section{Inverter Current-Voltage Solicitation}

This paper refers to a three-phase PM synchronous motor (PMSM) for the EV propulsion. The motor is supplied by a voltage source inverter (VSI) made of six switches with freewheeling diodes. A schematic diagram of the propulsion drive is shown in Figure 1, where $V_{B}$ is the voltage of the battery pack. Each motor phase is represented by its resistance $R_{x}$, inductance $L_{x}$, and sinusoidal back-emf $e_{x}, x$ being the generic motor phase $(x=a, b, c)$. Since the voltage drop across $R_{x}$ is usually much smaller than across $L_{x}$, the phase resistances are hereafter disregarded.

Let the inverter be commanded with the Space Vector Modulation (SVM) technique and the motor phase currents be kept sinusoidal in any working conditions, apart from the small ripple produced by the modulation. Then, the maximum magnitude of the phase voltage peak at the inverter output is

$$
V_{M}=\frac{V_{B}}{\sqrt{3}}
$$

and the general expression of the magnitudes of the motor phase voltages in the synchronously rotating coordinates $d-q$ is

$$
\begin{aligned}
V & =\sqrt{\left(E-\Omega_{e} L_{d} I_{d}\right)^{2}+\left(\Omega_{e} L_{q} I_{q}\right)^{2}} \\
& =\Omega_{e} \sqrt{\left(\frac{k}{p}-L_{d} I_{d}\right)^{2}+\left(L_{q} I_{q}\right)^{2}}
\end{aligned}
$$

where $E$ is the back-emf magnitude, $\Omega_{e}$ is the angular speed of the motor in electrical radians, $I_{q}$ and $I_{d}$ are the magnitudes of the current components in quadrature and in phase with the back-emf space phasor, $L_{d}$ and $L_{q}$ are the $d-q$ axis inductances, $k$ is the motor constant, and $p$ is the number of pole pairs of the motor.

When the motor speed is below the nominal one, $V$ is lower than $V_{M}, I_{d}$ is regulated at zero, and the motor currents are in phase with the back-emfs. In these conditions, the power converted from electrical to mechanical form is

$$
P=\frac{3}{2} E I_{q}=\frac{3}{2} k \Omega_{m} I_{q}
$$

where $\Omega_{m}$ is the angular speed of the motor in mechanical radians. The corresponding torque developed by the motor is

$$
T_{m}=\frac{3}{2} k I_{q}
$$

When the motor speed surpasses the nominal one, the motor is operated in the flux-weakening zone by forcing the phase currents to lead the back-emfs. This originates the component $I_{d}$ of the phase currents that compensates for the back-emf rise by partially counterbalancing the PM flux [14-16]. With a proper control of $I_{d}$, the voltage $V$ does not go beyond $V_{M}$ and the phase currents remain sinusoidal. In order that the rms value of the phase currents does not exceed the rated one, the onset of $I_{d}$ implies a fall of $I_{q}$ and, by (4), the motor develops a torque lower than in the constant-flux zone.

\section{Supply Period Device Power Losses}

Power losses in the devices are due to conduction [17] and switching [18] phenomena; they cause an increase of the operating temperature of the devices that, in turn, affects their characteristics [19]. Next subsections model the power losses in Si IGBTs, SiC MOSFETs, and freewheeling diodes when inserted in a three-phase inverter that supplies a propulsion motor and calculate the inverter losses in the supply period $T_{\text {sup }}$. Within $T_{\text {sup }}$, the power losses are the same in the six transistor-diode pairs of the inverter so that only the power 


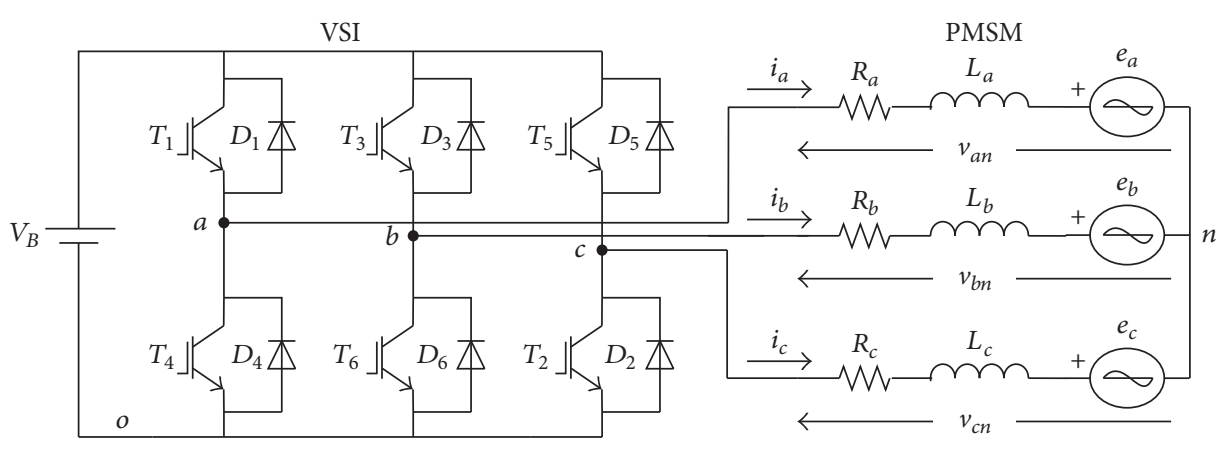

Figure 1: Propulsion drive diagram.

losses of the upper pair $T_{1}-D_{1}$ of Figure 1 are calculated. In order to simplify the analysis, $T_{\text {sup }}$ is assumed to be an even multiple $N$ of the switching period $T_{s}$ of the inverter, according to

$$
N=2 n=\frac{T_{\text {sup }}}{T_{s}} .
$$

Let the current of the phase $a$ have the following equation:

$$
I_{a}=I_{p} \sin (\theta),
$$

where $I_{p}$ is the peak value and $\theta$ is the instantaneous phase. Since the current flowing in $T_{1}$ and $D_{1}$ varies very little during $T_{s}$, in modeling the power losses in the devices due to the conduction, the current during the $i$ th switching period is assumed to be constant and equal to the amplitude that it has at the beginning of the switching period.

4.1. Si IGBT Loss Modeling. The conduction losses of Si IGBT $T_{1}$ in a supply period are given by

$$
P_{I, \text { cond }}=V_{\mathrm{CE}, 0} I_{I, \mathrm{avg}}+R_{\mathrm{CE}} I_{I, \mathrm{rms}}^{2},
$$

where the first term on the right-hand side represents the losses due to the saturation voltage $V_{\mathrm{CE}, 0}$ and the second term the losses in the ohmic resistance $R_{\mathrm{CE}}$. In (7), $I_{I, \text { avg }}$ and $I_{I, \mathrm{rms}}$ are the average and rms values of the collector current, respectively. Further to (5), (6) and the assumption of constant current within the switching period, $I_{I, \text { avg }}$ and $I_{I, \text { rms }}$ can be formulated as

$$
\begin{aligned}
& I_{I, \text { avg }}=\frac{1}{N} \sum_{i=0}^{n-1} I_{p}\left[\sin \left(\theta_{i}\right)\right] \delta_{i}, \\
& I_{I, \mathrm{rms}}=I_{p} \sqrt{\frac{1}{N} \sum_{i=0}^{n-1}\left[\sin \left(\theta_{i}\right)\right]^{2} \delta_{i},}
\end{aligned}
$$

where $\theta_{i}=2 \pi i / N$ is the instantaneous phase of the current at the beginning of the $i$ th switching period and $\delta_{i}$ is the $\mathrm{Si}$ IGBT duty-cycle [20, 21]. The summations in (8) and (9) are limited to the switching periods belonging to the first half of the supply period because Si IGBTs conduct only positive currents.
For the SVM technique, the duty-cycle can be expressed as

$$
\delta_{i}=\frac{1}{2}\left\{1+m\left\{\sin \left(\theta_{i}+\varphi\right)+0.15 \sin \left[3\left(\theta_{i}+\varphi\right)\right]\right\}\right\}
$$

by considering only the fundamental component and the third harmonic of the instantaneous duty-cycle. Symbols $m$ and $\varphi$ in (10) represent the modulation index and the phase shift of the voltage to the current.

By substituting (10) in (8) and (9) and by replacing the summations with the integrals, the average current in Si IGBT is calculated as

$$
I_{I, \mathrm{avg}}=I_{p}\left[\frac{1}{2 \pi}+\frac{m \cos (\varphi)}{8}\right]
$$

and the rms current as

$$
I_{I, \mathrm{rms}}=I_{p} \sqrt{\left\{\frac{1}{8}+\frac{m}{3 \pi}\left[\cos (\varphi)-\frac{0.15 \cos (3 \varphi)}{5}\right]\right\}} .
$$

The switching losses of Si IGBT are given by (13), where $E_{I, \text { on }}$ and $E_{I, \text { off }}$ are the energies lost, respectively, in its turn-on and turn-off, and $f_{s}$ is the switching frequency.

$$
P_{I, \mathrm{sW}}=\left(E_{I, \mathrm{on}}+E_{I, \mathrm{off}}\right) f_{s} .
$$

Total losses of Si IGBT $T_{1}$ are the sum of conduction and switching losses; as a whole, the losses in the six Si IGBTs of the inverter are six times higher, resulting in

$$
P_{I, T}=6\left(P_{I, \mathrm{cond}}+P_{I, \mathrm{sw}}\right) .
$$

4.2. SiC MOSFET Loss Modeling. The conduction losses of $\mathrm{SiC}$ MOSFET $T_{1}$ in a supply period are given by

$$
P_{M \text {, cond }}=R_{d s(\text { on })} I_{M, \text { rms }}^{2} \text {, }
$$

where $R_{d s(\text { on) }}$ is the on-resistance and $I_{M \text {,rms }}$ is the rms drain current. Differently from (9) the rms current in SiC MOSFET is expressed as

$$
I_{M, \mathrm{rms}}=I_{p} \sqrt{\frac{1}{N} \sum_{i=0}^{N-1}\left[\sin \left(\theta_{i}\right)\right]^{2} \delta_{i}}
$$


with the summation extended to the entire supply period. This is because SiC MOSFETs are bidirectional devices and have a drain-source voltage lower than the antiparallel diode. Therefore, SiC MOSFET $T_{1}$, apart from the dead-times, conducts the phase current even when it is negative and the companion $\mathrm{SiC}$ MOSFET $T_{4}$ of the same leg is off. By substituting (10) in (16) and solving, $I_{M, \text { rms }}$ is calculated in

$$
I_{M, \mathrm{rms}}=\frac{I_{p}}{2}
$$

and the conduction losses of SiC MOSFET become

$$
P_{M, \text { cond }}=R_{d s(\text { on })} \frac{I_{p}^{2}}{4} .
$$

Likewise for Si IGBT, switching losses of SiC MOSFET are given by (19), where $E_{M \text {,on }}$ and $E_{M \text {,off }}$ are the energies lost, respectively, in turning-on and turning-off the transistor, and $f_{s}$ is the switching frequency.

$$
P_{M, \mathrm{sw}}=\left(E_{M, \mathrm{on}}+E_{M, \mathrm{off}}\right) f_{s} .
$$

As a whole, the losses in the six SiC MOSFETs of the inverter are

$$
P_{M, T}=6\left(P_{M, \text { cond }}+P_{M, \text { sw }}\right)
$$

4.3. Diode Loss Modeling. The conduction losses of a diode in a supply period are

$$
P_{D, \text { cond }}=V_{F} I_{D, \text { avg }}+R_{d} I_{D, \mathrm{rms}}^{2}
$$

where $V_{F}$ is the threshold voltage, $R_{d}$ is the direct resistance, and $I_{D \text {,avg }}$ and $I_{D \text {,rms }}$ are the average and rms values of the current flowing through the diode.

For the Si IGBT inverter, $I_{D \text {,avg }}$ and $I_{D \text {,rms }}$ are expressed by (22) and (23), respectively. They are derived from (8) and (9) by recognizing that diode $D_{1}$ conducts during the on-time of Si IGBT $T_{1}$ when the phase current is negative

$$
\begin{aligned}
& I_{D, \text { avg }}=-\frac{1}{N} \sum_{i=n}^{N-1} I_{p}\left[\sin \left(\theta_{i}\right)\right] \delta_{i}, \\
& I_{D, \mathrm{rms}}=I_{p} \sqrt{\frac{1}{N} \sum_{i=n}^{N-1}\left[\sin \left(\theta_{i}\right)\right]^{2} \delta_{i} .}
\end{aligned}
$$

By manipulating (22) and (23) as for the Si IGBT inverter, they become

$$
\begin{aligned}
I_{D, \mathrm{avg}} & =I_{p}\left[\frac{1}{2 \pi}-\frac{m \cos (\varphi)}{8}\right], \\
I_{D, \mathrm{rms}} & =I_{p} \sqrt{\frac{1}{8}-\frac{m}{3 \pi}\left[\cos (\varphi)-\frac{0.15 \cos (3 \varphi)}{5}\right]} .
\end{aligned}
$$

For SiC MOSFET inverter, the diodes are flown by current only during the dead-times. Since the latter ones are much shorter than the switching period, the conduction losses
TABLE 1: Battery pack characteristics.

\begin{tabular}{lc}
\hline Nominal voltage & $365 \mathrm{~V}$ \\
Maximum voltage & $400 \mathrm{~V}$ \\
Minimum voltage & $250 \mathrm{~V}$ \\
Stored energy & $24 \mathrm{~kW} \cdot \mathrm{h}$ \\
Maximum power & $90 \mathrm{~kW}$ \\
Nominal current & $69 \mathrm{~A}$ \\
Maximum current & $360 \mathrm{~A}$ \\
\hline
\end{tabular}

TABLE 2: Propulsion motor characteristics.

\begin{tabular}{lcc}
\hline Nominal power & $P_{N}$ & $80 \mathrm{~kW}$ \\
Nominal torque & $T_{N}$ & $280 \mathrm{~N} \cdot \mathrm{m}$ \\
Nominal current & $I_{N}$ & $250 \mathrm{~A}$ \\
Motor constant & $k$ & $0.58 \mathrm{~V} \cdot \mathrm{s} / \mathrm{rad}$ \\
$d$ axis inductance & $L_{d}$ & $3.3 \mathrm{mH}$ \\
$q$ axis inductance & $L_{q}$ & $1.2 \mathrm{mH}$ \\
Number of pole pairs & $n_{p}$ & 1 \\
Maximum speed & $\omega_{m}$ & $10390 \mathrm{rpm}$ \\
Mass & $m$ & $58 \mathrm{~kg}$ \\
\hline
\end{tabular}

in the diodes are negligible with respect to those in $\mathrm{SiC}$ MOSFETs.

Both in the Si IGBT and in SiC MOSFET inverters, switching losses of the diodes must be added. Most of them are due to the reverse recovery losses so that the remaining part can be ignored. These losses are given by

$$
P_{D, \mathrm{sw}}=\left(Q_{\mathrm{rr}} V_{d}\right) f_{s},
$$

where $Q_{\mathrm{rr}}$ is the reverse recovery charge, $V_{d}$ is the voltage across the diode during reverse recovery, here equal to $V_{B}$, and $f_{s}$ is the switching frequency.

4.4. Total Inverter Losses. The total losses of the Si IGBT and $\mathrm{SiC}$ MOSFET inverters are given by

$$
\begin{aligned}
P_{\mathrm{Si}-\text { inv }} & =P_{I, T}+6 P_{D, \text { cond }}+6 P_{D, \mathrm{sw}}, \\
P_{\mathrm{SiC} \text {-inv }} & =P_{M, T}+6 P_{D, \mathrm{sw}} .
\end{aligned}
$$

By (14), (20), (21), and (25), the total losses are expressed in terms of peak phase current, modulation index, battery voltage, and device parameters.

\section{Study Case}

The C-segment compact electric car in [22] is taken as a study case to evaluate the improvement in the inverter efficiency achievable by replacing the Si IGBT inverter with a SiC MOSFET one. The characteristics of the car battery pack and the propulsion motor of PMSM type are reported in Tables 1 and 2, respectively. The motor parameters have been obtained by help of a cross examination of the data in [23] and the relevant literature [24].

From the battery and motor data, it has been hypothesized that the Si IGBTs used in the propulsion inverter have 
TABLE 3: Si IGBT and SiC MOSFET characteristics.

\begin{tabular}{lcc}
\hline Parameters & Si IGBT & SiC MOSFET \\
\hline Part number & MG12100W-XN2MM & CAS100H12AM1 \\
Manufacturer & Littelfuse & Wolfspeed \\
$V_{\mathrm{DS}, \max }$ & $1200 \mathrm{~V}$ & $1200 \mathrm{~V}$ \\
$I_{D, \max }$ & $140 \mathrm{~A} @ 25^{\circ} \mathrm{C}$ & $168 \mathrm{~A} @ 25^{\circ} \mathrm{C}$ \\
$V_{G}$ & $15 \mathrm{~V}$ & $20 \mathrm{~V}$ \\
$R_{\mathrm{CE}, \text { on }}-R_{\mathrm{DS}, \text { on }}$ & $8 \mathrm{~m} \Omega @ 25^{\circ} \mathrm{C}$ & $16 \mathrm{~m} \Omega @ 25^{\circ} \mathrm{C}$ \\
& $11.5 \mathrm{~m} \Omega @ 125^{\circ} \mathrm{C}$ & $20 \mathrm{~m} \Omega @ 150^{\circ} \mathrm{C}$ \\
$V_{\mathrm{CE}, 0}$ & $0.7 \mathrm{~V} @ 25^{\circ} \mathrm{C}$ & - \\
$E_{\text {on }}$ & $0.65 \mathrm{~V} @ 125^{\circ} \mathrm{C}$ & - \\
$E_{\text {off }}$ & $7.8 \mathrm{~mJ} @ 600 \mathrm{~V}, 100 \mathrm{~A}$ & $2.4 \mathrm{~mJ} @ 800 \mathrm{~V}, 100 \mathrm{~A}$ \\
$V_{F}$ & $8 \mathrm{~mJ} @ 600 \mathrm{~V}, 100 \mathrm{~A}$ & $1.3 \mathrm{~mJ} @ 800 \mathrm{~V}, 100 \mathrm{~A}$ \\
& $1.65 \mathrm{~V} @ 100 \mathrm{~A}, 25^{\circ} \mathrm{C}$ & $1.8 \mathrm{~V} @ 100 \mathrm{~A}, 25^{\circ} \mathrm{C}$ \\
$R_{d}$ & $1.65 \mathrm{~V} @ 100 \mathrm{~A}, 125^{\circ} \mathrm{C}$ & $2.5 \mathrm{~V} @ 100 \mathrm{~A}, 150^{\circ} \mathrm{C}$ \\
$Q_{\mathrm{rr}}$ & $4.5 \mathrm{~m} \Omega @ 25^{\circ} \mathrm{C}$ & $8.5 \mathrm{~m} \Omega @ 25^{\circ} \mathrm{C}$ \\
\hline
\end{tabular}

characteristics like the item with part number MG12100WXN2MM by Littelfuse; its characteristics are reported in the central column of Table 3. The safety operating area of this device is nearly rectangular, bounded by a collector current of $200 \mathrm{~A}$ and a collector-emitter voltage of about $1150 \mathrm{~V}$ [25]. For $\mathrm{SiC}$ MOSFETs, the item with part number CAS100H12AM1 by Wolfspeed has been selected because its characteristics are similar to those of the Si IGBT item; they are reported in the right column of Table 3 [26]. The last three rows of the table include the parameters of the freewheeling diode integrated in Si IGBT and SiC MOSFET, respectively. In Section 7, the impact of the temperature on the inverter efficiency is investigated; for this reason, the table reports the device parameters at a junction temperature of both $25^{\circ} \mathrm{C}$ and $125^{\circ} \mathrm{C}\left(150^{\circ} \mathrm{C}\right.$ for $\mathrm{SiC}$ MOSFET). For Si IGBT, parameter $Q_{\mathrm{rr}}$ has been estimated from the reverse recovery time at $125^{\circ} \mathrm{C}$ and the reverse peak current. The data sheets of different transistors with comparable characteristics reveal that $Q_{\mathrm{rr}}$ increases of about four times when the temperature rises from $25^{\circ} \mathrm{C}$ to $125^{\circ} \mathrm{C}$; consequently, at $25^{\circ} \mathrm{C}$, a $Q_{\mathrm{rr}}$ value four times smaller of that listed in the table has been used. For $\mathrm{SiC}$ MOSFET, instead, $Q_{\mathrm{rr}}$ is a temperature-independent quantity and hence the value at $25^{\circ} \mathrm{C}$ has been used at $150^{\circ} \mathrm{C}$ as well [27].

\section{Efficiency Estimation}

The efficiency maps of the inverters in the torque-speed plane are calculated using the power loss formulae in Section 4 , with the switching frequency $f_{s}$ set at $10 \mathrm{kHz}$ and a junction temperature of $25^{\circ} \mathrm{C}$. The device data are fetched out from Table 3, while the battery voltage is fetched out from Table 1. Notably, the efficiency maps are drawn as a function of torque and speed of the propulsion motor, while the power loss formulae are expressed in terms of inverter voltage and current. To get the maps, torque and speed at the motor working points are turned into current and voltage by

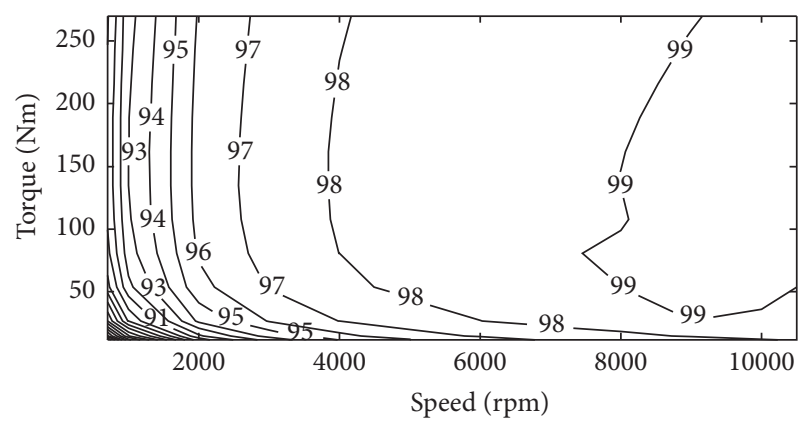

FIGURE 2: Si IGBT inverter efficiency map.

help of the relationships found in Section 3 and the motor parameters given in Table 2. In particular, for each torque and speed pair, the magnitudes of the motor phase voltage and current and their phase shift have been computed and, from the phase and battery voltages, $m$ has been derived. Afterwards, the computed values have been inserted in (11), (12), (17), and (24) to obtain the current magnitudes needed to estimate the conduction losses of transistors and diodes. For the estimation of the switching losses, $E_{\text {on }}$ and $E_{\text {off }}$ reported in the data sheets have been adjusted according to the actual amplitude of the phase current, being the losses about proportional to the transistor drain/collector current. A similar adjustment of $E_{\text {on }}$ and $E_{\text {off }}$ has been done to account for the fact that they are specified at a voltage different from the battery voltage of the study case.

6.1. Si IGBT Inverter Efficiency. The efficiency map of the Si IGBT inverter is drawn in Figure 2. It shows that the efficiency is around $99 \%$ when operating at speeds exceeding $8000 \mathrm{rpm}$ and decreases appreciably at low speed, irrespectively from the torque. This can be readily recognized from the fact that, in spite of the high torques, the power levels are relatively small at low speeds (f.i. less than $2000 \mathrm{rpm}$ ), while the switching losses are almost constant.

6.2. SiC MOSFET Inverter Efficiency. The efficiency map of the $\mathrm{SiC}$ MOSFET inverter, calculated in the same torque and speed range of the motor as for the Si IGBT inverter, is drawn in Figure 3. It shows that the efficiency is around 99\% in the speed interval between 5000 and $10000 \mathrm{rpm}$, thus exceeding $1 \%$ the efficiency of the Si IGBT inverter in the speed interval from 3500 and $8000 \mathrm{rpm}$, provided that the torque is less than half the maximum. Also, in the case of the SiC MOSFET inverter, the efficiency decreases at low speed, but, even in the worst case, it is about $4 \%$ higher than in the Si IGBT counterpart.

6.3. Overall Propulsion Drive Efficiency. The overall efficiency of the propulsion drive is computed by multiplying the inverter efficiency by the motor efficiency, as specified in [23]. The advantage in the overall efficiency ensuing from the $\mathrm{SiC}$ MOSFET inverter is illustrated by the incremental efficiency map of Figure 4. From the map, the fact emerges that the SiC MOSFET propulsion drive exhibits an overall 
TABLE 4: Propulsion drive efficiency.

\begin{tabular}{|c|c|c|c|c|c|}
\hline Number & Speed [rpm] & Torque $[\mathrm{N} \cdot \mathrm{m}]$ & $\begin{array}{c}\text { With SiC MOSFET } \\
\text { inverter (calculated) [\%] }\end{array}$ & $\begin{array}{c}\text { With Si IGBT inverter } \\
\text { (calculated) }[\%]\end{array}$ & $\begin{array}{c}\text { With Si IGBT inverter } \\
\text { (measured) [\%] }\end{array}$ \\
\hline 1 & 1144 & 154 & 88.85 & 86.06 & 86.63 \\
\hline 2 & 1246 & 63 & 92.45 & 89.04 & 87.81 \\
\hline 3 & 1376 & 82 & 92.60 & 89.70 & 88.00 \\
\hline 4 & 1394 & 142 & 90.20 & 88.18 & 87.20 \\
\hline 5 & 1997 & 108 & 93.35 & 91.60 & 90.42 \\
\hline 6 & 2006 & 37 & 93.65 & 90.79 & 90.12 \\
\hline 7 & 2549 & 84 & 94.65 & 92.89 & 91.48 \\
\hline 8 & 2785 & 115 & 94.75 & 93.28 & 93.28 \\
\hline 9 & 2954 & 98 & 95.10 & 93.66 & 93.31 \\
\hline 10 & 2984 & 51 & 94.85 & 93.07 & 92.68 \\
\hline 11 & 3020 & 87 & 95.20 & 93.72 & 93.11 \\
\hline 12 & 3142 & 48 & 94.95 & 93.09 & 92.17 \\
\hline 13 & 3425 & 74 & 95.40 & 94.05 & 93.63 \\
\hline 14 & 4709 & 23 & 94.15 & 92.16 & 92.01 \\
\hline 15 & 4786 & 62 & 95.90 & 94.79 & 94.48 \\
\hline 16 & 5067 & 48 & 95.25 & 94.30 & 93.80 \\
\hline 17 & 5451 & 36 & 94.85 & 93.54 & 93.05 \\
\hline 18 & 6018 & 33 & 94.55 & 93.31 & 93.59 \\
\hline 19 & 6436 & 42 & 95.05 & 93.93 & 94.61 \\
\hline 20 & 7128 & 42 & 95.15 & 94.04 & 93.38 \\
\hline 21 & 7490 & 45 & 95.25 & 94.24 & 94.35 \\
\hline 22 & 8186 & 47 & 95.40 & 94.41 & 95.23 \\
\hline 23 & 8232 & 31 & 94.35 & 93.28 & 93.86 \\
\hline 24 & 8270 & 24 & 93.85 & 91.73 & 92.65 \\
\hline
\end{tabular}

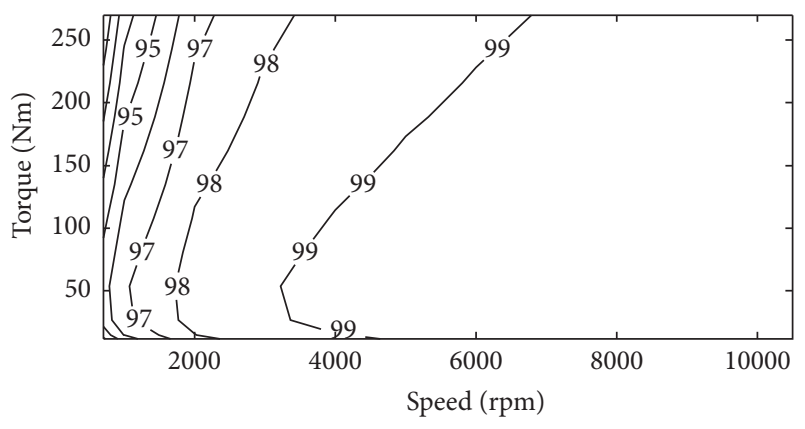

FIgURE 3: SiC MOSFET inverter efficiency map.

efficiency higher than $1 \%$ over most of the working points, the improvement being higher than $5 \%$ at low speeds and torques. Efficiency of the propulsion drive with the $\mathrm{SiC}$ MOSFET and Si IGBT inverters, calculated for a few motor torque-speed pairs, is reported in Table 4; for an easier comparison, the efficiency is also plotted in Figure 5 as a function of the motor torque.

6.4. Range Extension Due to Improved Efficiency. The improvement in the efficiency of the propulsion drive with

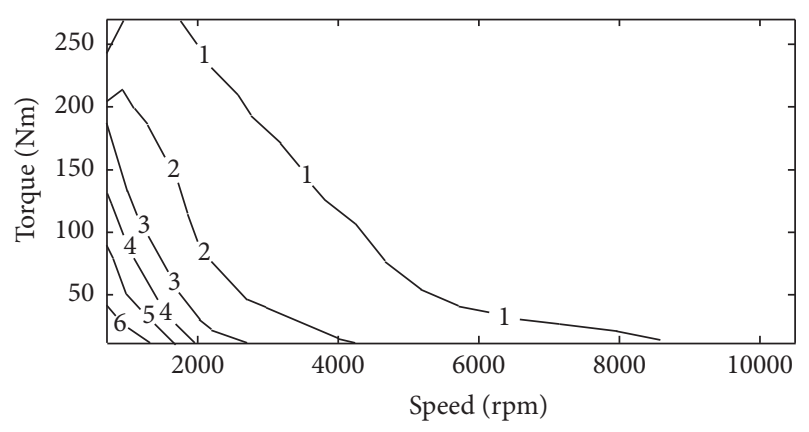

FIGURE 4: Incremental efficiency of the SiC MOSFET propulsion drive over the Si IGBT one at $25^{\circ} \mathrm{C}$.

the $\mathrm{SiC}$ MOSFET inverter extends the $\mathrm{EV}$ range. Let us estimate the range increase of EV of the study case when the motor runs at given speed and torque. The power supplied by the battery for a motor speed of $\Omega_{m}$ and a torque of $T_{m}$ is

$$
P_{B}=\frac{T_{m} \Omega_{m}}{\eta},
$$




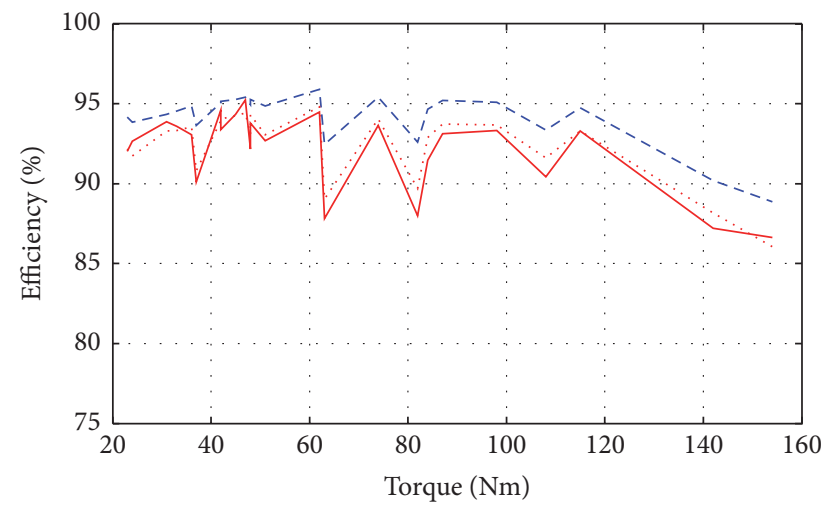

FIgURE 5: Computed efficiency of the SiC MOSFET (blue dashed line) and Si IGBT (red dotted line) propulsion drives as per Table 4 and measured efficiency of the Si IGBT (red solid line) propulsion drive versus motor torque.

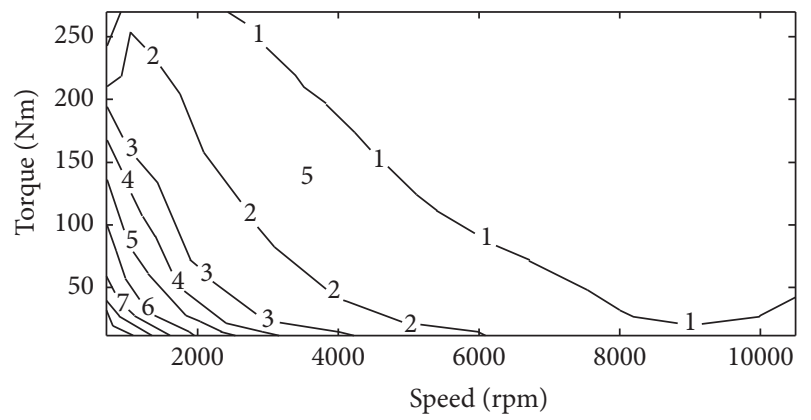

FIGURE 6: Incremental efficiency of the SiC MOSFET propulsion drive over that with Si IGBTs at $125^{\circ} \mathrm{C}$.

where $\eta$ is the efficiency of the propulsion drive. If the battery delivers the energy $E$ before being recharged and $\mathrm{EV}$ moves at the constant speed $v$, the range is

$$
r=\frac{E}{P_{B}} v
$$

For equal values of $E$ and $v$, the increase in the range achieved by replacing the Si IGBT inverter with the SiC MOSFET one, expressed in percent, is

$$
\begin{aligned}
\Delta r_{\%} & \triangleq \frac{r_{\mathrm{SiC}, \text { inv }}-r_{\mathrm{Si}, \text { inv }}}{r_{\mathrm{Si}, \text { inv }}} \\
& =\frac{\left(E / P_{B, \mathrm{Sic} \text {,inv }}\right) v-\left(E / P_{B, \mathrm{Si}, \text { inv }}\right) v}{\left(E / P_{B, \mathrm{Si} \text { inv }}\right) v}=\frac{\eta_{\mathrm{SiC}, \text { inv }}}{\eta_{\mathrm{Si} \text { inv }}}-1 .
\end{aligned}
$$

Picking as an example some torque-speed pairs and the relevant efficiency from Table 4, the resultant percentage increases in the range are reported in Table 5. Inspection of the table shows that the range lengthens up to $3.8 \%$ when the propulsion motor operates at low speeds and high torques, as it happens when the car is climbing a hill or pulling a load, while, at high speeds and low torques, the advantage of the $\mathrm{SiC}$ MOSFET inverter reduces to about $1 \%$. The results agree with the map of Figure 4, whereby it points out that the
TABLE 5: Estimated range.

\begin{tabular}{lc}
\hline Number & $\begin{array}{c}\text { Range extension with SiC MOSFET } \\
\text { inverter [\%] }\end{array}$ \\
\hline 1 & 3.24 \\
2 & 3.80 \\
34 & 3.23 \\
21 & 1.07 \\
22 & 1.05 \\
23 & 1.15 \\
\hline
\end{tabular}

maximum improvement in the efficiency of the SiC MOSFET propulsion drive is reached at low speeds and high torques.

\section{Temperature Effect}

Rise of the operating temperature causes a variation of the parameters of both $\mathrm{Si}$ and $\mathrm{SiC}$ devices, thus affecting the efficiency of the inverter. This issue has been investigated by recalculating the efficiency of the propulsion drive with the parameters relevant to a junction temperature of $125^{\circ} \mathrm{C}$ for Si IGBTs of the inverter and $150^{\circ} \mathrm{C}$ for SiC MOSFETs. The new map of the incremental efficiency of the SiC MOSFET propulsion drive over that with Si IGBTs is reported in Figure 6. By comparing it with the map in Figure 4, it turns out that (i) the improvement in the efficiency of the propulsion drive with SiC MOSFET inverter increases as the operating temperature raises and (ii) this effect is sensibly greater in the low speed region.

\section{Investigation Validation}

The calculated results on the overall efficiency of the propulsion drive with the Si IGBT inverter have been validated by means of data measured on $\mathrm{EV}$ of the study case.

Real-time data on (i) speed of EV, (ii) torque and speed of the motor, and (iii) voltage, current, and state of charge of the battery have been gathered by means of the Advantech TREK 550 automotive PC. It was connected to the EV electronic diagnostic system through the On Board Diagnostic (OBD) port, which operates according to SAEJ1979 [28] and ISO15765 standards. Details about the protocol used by the manufacturer to code the different quantities can be found in the forum [29]. The accuracy of the collected data has been assessed in a previous work [30], where they have been used to develop a chart of the consumption and the emissions of conventional and hybrid vehicles.

The automotive PC was starting the data acquisition every time the car was turned on and, as soon as a Wi-Fi connection was made accessible, was downloading the acquired data in a remote server together with the position detected by a global positioning system. Figure 7 reports a schematic of the experimental platform, while Figure 8 shows a screenshot of the graphical interface that enables the user to retrieve the data stored in the remote server.

By processing the acquired data, the efficiency of the propulsion drive of $\mathrm{EV}$ has been determined at different 


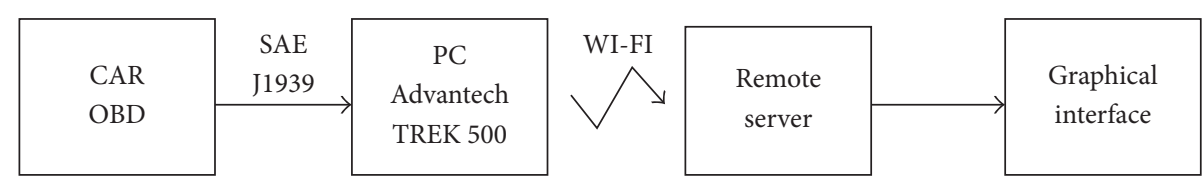

FIGURE 7: Experimental platform schematic.

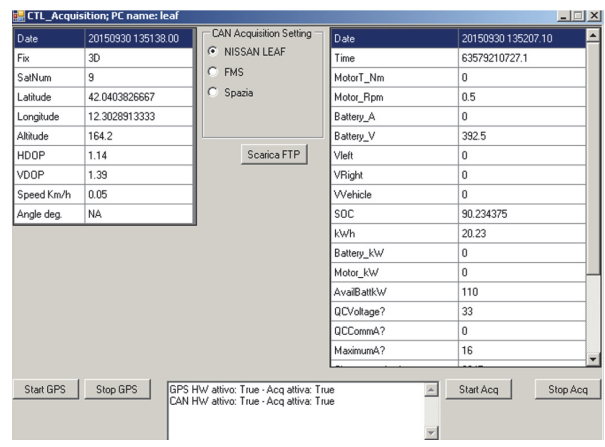

FIGURE 8: Graphical interface.

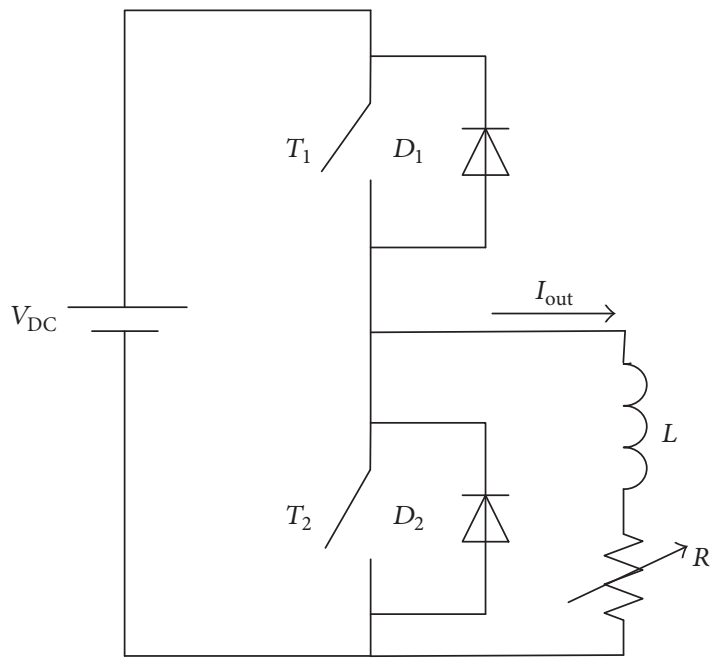

FIgURE 9: Test bench circuit. torque-speed working points. Results pertinent to Table 4 are listed in its right-hand side column and plotted with the red solid line in Figure 5. Going over the table, it is evident that the measured values of efficiency for the propulsion drive match the computed ones with a difference that, in most of the points, is lower than $1 \%$ and never exceeds $1.5 \%$. One can also infer from the results that the loss model is not biased and that it is not affected by systematic errors, since the computed values of efficiency sometimes are a bit smaller and sometimes are a bit greater than the measured values. Summing up, the results confirm the effectiveness of the loss model developed for the Si IGBT inverter.

Regarding the SiC MOSFET inverter, the loss model of the SiC MOSFET has been verified by arranging the test bench described in Appendix and by comparing the efficiency calculated from the model with that measured from the circuit. The measurements confirmed the validity of the loss model, thus corroborating the efficiency results obtained for the SiC MOSFET inverter. Explicitly, Figure 10 in Appendix underlines that the computed efficiency differs from the measured one of a quantity that never exceeds $1 \%$, reaching this value at high currents and low voltages.

Putting together the results found above, it can be concluded that the SiC MOSFET propulsion drive outperforms the efficiency of the Si IGBT one of a few percent over most of the regions of the torque-speed plane, whereby the exact amount of the improvement, like in any engineering approach, should account for the measurement errors and data tolerances. According to the outcomes of the experiment described in Appendix, the maximum margin of inaccuracy of $1 \%$ is reached in the high torque-low speed region.

\section{Conclusions}

The paper has explored the improvement in the efficiency of a propulsion inverter for $\mathrm{EV}$, achievable by replacing the $\mathrm{Si}$ IGBTs of the propulsion inverter with SiC MOSFETs. After finding out the voltage-current solicitations for the inverter as a function of the motor torque and speed, and modeling the power losses of the two types of device as a function of such solicitations, the efficiency of the SiC MOSFET inverter against the Si IGBT one has been first calculated and then combined with the efficiency of the propulsion motor to determine the overall efficiency of the propulsion drive. The results, applied to the study case of a marketed C-segment compact electric car, have demonstrated the achievement of an overall efficiency that, in some region of the torque-speed plane, is up to $5 \%$ greater, with a consequent extension of the car range. The results of efficiency for the propulsion drive with the Si IGBT inverter have been supported by measurements. The loss model for the SiC MOSFET inverter has been validated experimentally, thus corroborating the results obtained for the efficiency of the relevant propulsion drive.

\section{Appendix}

The test bench circuit, made of an inverter leg and drawn in Figure 9, has been built up around two SiC MOSFETs with part number SCT2120AF by ROHM semiconductor [31]. Main characteristics of the circuit are DC voltage $V_{\mathrm{DC}}$ of $100 \mathrm{~V}$, switching frequency of $10 \mathrm{kHz}$, inductance $L$ of 


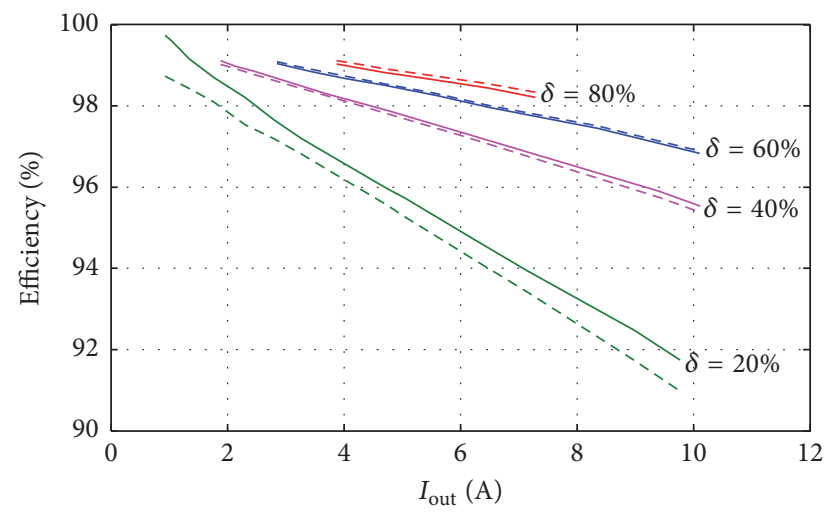

Figure 10: Measured (solid line) and estimated (dashed line) efficiency of the test bench circuit.

$3 \mathrm{mH}$, and load resistance $R$ adjustable from 0 to $20 \Omega$. The circuit has been operated at different currents and dutycycles, and the input and output powers have been measured with the digital wattmeter WT1800 by Yokogawa. The efficiency obtained from the measured data has been compared with that computed applying the loss model developed in Section 4. The results are traced in Figure 10 as a function of the current and for different values of the duty-cycle. The good correspondence between measured and calculated data, substantiated by a difference that never exceeds $1 \%$, confirms the validity of the SiC MOSFET loss model.

\section{Competing Interests}

The authors declare that there is no conflict of interests regarding the publication of this paper.

\section{References}

[1] M. Bertoluzzo and G. Buja, "Development of electric propulsion systems for light electric vehicles," IEEE Transactions on Industrial Informatics, vol. 7, no. 3, pp. 428-435, 2011.

[2] V. I. Patel, J. Wang, D. T. Nugraha, R. Vuletić, and J. Tousen, "Enhanced availability of drivetrain through novel multiphase permanent-magnet machine drive," IEEE Transactions on Industrial Electronics, vol. 63, no. 1, pp. 469-480, 2016.

[3] K. M. Rahman, S. Jurkovic, C. Stancu, J. Morgante, and P. J. Savagian, "Design and Performance of Electrical Propulsion System of Extended Range Electric Vehicle (EREV) Chevrolet Volt," IEEE Transactions on Industry Applications, vol. 51, no. 3, pp. 2479-2488, 2015.

[4] Q. Guo, C. Zhang, L. Li, J. Zhang, J. Liu, and T. Wang, "Efficiency optimization control of permanent-magnet synchronous machines for electric vehicle traction systems," in Proceedings of the IEEE Vehicle Power and Propulsion Conference (VPPC '16), pp. 1-5, Hangzhou, China, October 2016.

[5] I. Abuishmais and T. M. Undeland, "SiC devices for renewable and high performance power conversion applications," Advances in Power Electronics, vol. 2012, Article ID 765619, 5 pages, 2012.

[6] V. Veliadis, T. McNutt, M. Snook et al., "Large area silicon carbide vertical JFETs for $1200 \mathrm{~V}$ cascode switch operation,"
International Journal of Power Management Electronics, vol. 2008, Article ID 523721, 8 pages, 2008.

[7] S. Jahdi, O. Alatise, C. Fisher, L. Ran, and P. Mawby, "An evaluation of silicon carbide unipolar technologies for electric vehicle drive-trains," IEEE Journal of Emerging and Selected Topics in Power Electronics, vol. 2, no. 3, pp. 517-528, 2014.

[8] X. Wang, C. Jiang, B. Lei, H. Teng, H. K. Bai, and J. L. Kirtley, "Power-loss analysis and efficiency maximization of a siliconcarbide MOSFET-based three-phase 10-kW bidirectional EV charger using variable-DC-bus control," IEEE Journal of Emerging and Selected Topics in Power Electronics, vol. 4, no. 3, pp. 880892, 2016.

[9] A. Trentin, L. Empringham, L. de Lillo, P. Zanchetta, P. Wheeler, and J. Clare, "Experimental efficiency comparison between a direct matrix converter and an indirect matrix converter using both Si IGBTs and SiC mosfets," IEEE Transactions on Industry Applications, vol. 52, no. 5, pp. 4135-4145, 2016.

[10] S. Ozdemir, F. Acar, and U. S. Selamogullari, "Comparing different switching techniques for silicon carbide MOSFET assisted silicon IGBT based hybrid switch," in Proceedings of the 5th International Conference on Electrical Engineering and Informatics (ICEEI '15), pp. 558-561, IEEE, Denpasar, Bali, Indonesia, August 2015.

[11] T. Daranagama, F. Udrea, T. Logan, and R. McMahon, "A performance comparison of $\mathrm{SiC}$ and $\mathrm{Si}$ devices in a bi-directional converter for distributed energy storage systems," in Proceedings of the IEEE 7th International Symposium on Power Electronics for Distributed Generation Systems (PEDG '16), pp. 1-8, IEEE, Vancouver, Canada, June 2016.

[12] D. Han, J. Noppakunkajorn, and B. Sarlioglu, "Analysis of a $\mathrm{SiC}$ three-phase voltage source inverter under various current and power factor operations," in Proceedings of the 39th Annual Conference of the IEEE Industrial Electronics Society (IECON '13), pp. 447-452, IEEE, Vienna, Austria, November 2013.

[13] K. Kumar, M. Bertoluzzo, and G. Buja, "Impact of SiC MOSFET traction inverters on compact-class electric car range," in Proceedings of the IEEE International Conference on Power Electronics, Drives and Energy Systems (PEDES '14), pp. 1-6, IEEE, Mumbai, India, December 2014.

[14] M. Zeraoulia, M. E. H. Benbouzid, and D. Diallo, "Electric motor drive selection issues for HEV propulsion systems: a comparative study," IEEE Transactions on Vehicular Technology, vol. 55, no. 6, pp. 1756-1764, 2006.

[15] A. Shakal, Y. Liao, and T. A. Lipo, "A permanent magnet ac machine structure with true field weakening capability," Electric Machines and Power Systems, vol. 24, no. 5, pp. 497-509, 1996.

[16] N. Urasaki, Y. Noguchi, A. M. Howlader, Y. Yonaha, A. Yona, and T. Senjyu, "Wide-speed range operation of interior permanent magnet synchronous motor with parameter identification," Electric Power Components and Systems, vol. 37, no. 8, pp. 847-865, 2009.

[17] M. G. Hosseini Aghdam, S. H. Fathi, and G. B. Gharehpetian, "A novel switching algorithm to balance conduction losses in power semiconductor devices of multi-level cascade inverters," Electric Power Components and Systems, vol. 36, no. 12, pp. 12531281, 2008.

[18] P. K. Chaturvedi, S. Jain, P. Agrawal, R. K. Nema, and K. K. Sao, "Switching losses and harmonic investigations in multilevel inverters," IETE Journal of Research, vol. 54, no. 4, pp. 297-307, 2008.

[19] M. Denk, M.-M. Bakran, and P. Bauer, "Online junction temperature cycle recording of an IGBT power module in a 
hybrid car," Advances in Power Electronics, vol. 2015, Article ID 652389, 14 pages, 2015.

[20] S. S. Williamson, A. Emadi, and K. Rajashekara, "Comprehensive efficiency modeling of electric traction motor drives for hybrid electric vehicle propulsion applications," IEEE Transactions on Vehicular Technology, vol. 56, no. 4, pp. 1561-1572, 2007.

[21] H. Zhang, L. M. Tolbert, and B. Ozpineci, "Impact of SiC devices on hybrid electric and plug-in hybrid electric vehicles," IEEE Transactions on Industry Applications, vol. 47, no. 2, pp. 912-921, 2011.

[22] http://www.mynissanleaf.com.

[23] Annual Progress Report on Advanced Power Electronics and Electric Motors Program, U.S. Department of Energy, January 2013, http://wwwl.eere.energy.gov/vehiclesandfuels/pdfs/ program/2012_apeem_report.pdf.

[24] J. Faiz, M. Ghaneei, A. Keyhani, and A. B. Proca, "Optimum design of induction motors for electric vehicles," Electric Machines \& Power Systems, vol. 28, no. 12, pp. 1177-1194, 2000.

[25] http://www.littelfuse.com/ /media/electronics/datasheets/ power_semiconductors $\% 20 /$ littelfuse_power_semiconductor_ igbt_module_mg12100w_xn2mm_datasheet.pdf.pdf.

[26] http://www.mouser.com/ds/2/90/CAS100H12AM1-475725.pdf.

[27] S. Davis, "Schottky diodes: the old ones are good, the new ones are better," in Design Feature, Power Electronics Technology, 2011, http://powerelectronics.com/site-files/powerelectronics.com/ files/archive/powerelectronics.com/images/SchottkyDiodes.pdf.

[28] HS3000, On-Board Diagnostics for Light and Medium Duty Vehicles Standards Manual, SAE International, 2010.

[29] http://www.mynissanleaf.com/viewforum.php?f=44.

[30] A. Alessandrini, F. Filippi, F. Orecchini, and F. Ortenzi, "A new method for collecting vehicle behaviour in daily use for energy and environmental analysis," Proceedings of the Institution of Mechanical Engineers, Part D: Journal of Automobile Engineering, vol. 220, no. 11, pp. 1527-1537, 2006.

[31] http://rohmfs.rohm.com/en/products/databook/datasheet/discrete/sic/mosfet/sct2120af-e.pdf. 


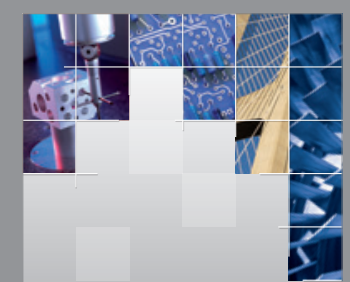

\section{Enfincering}
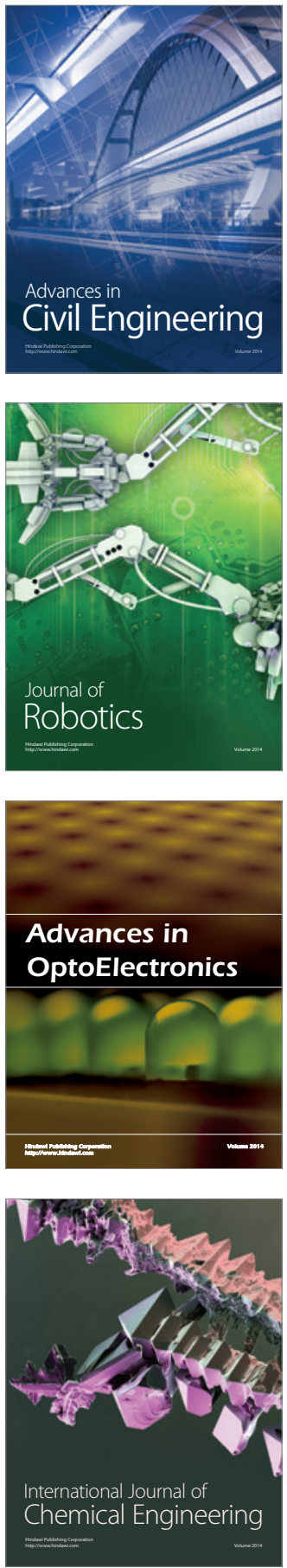

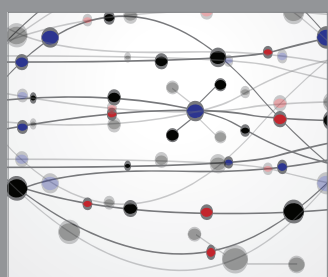

The Scientific World Journal

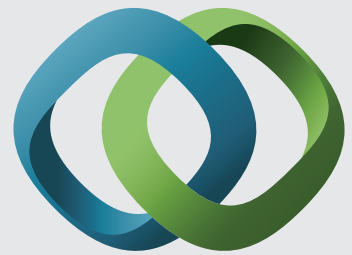

\section{Hindawi}

Submit your manuscripts at

https://www.hindawi.com
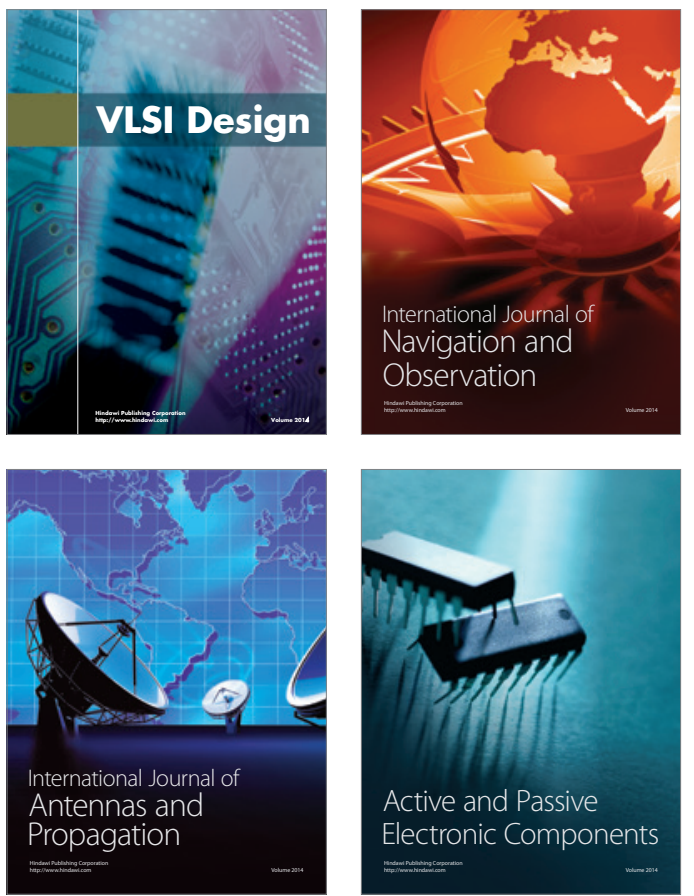
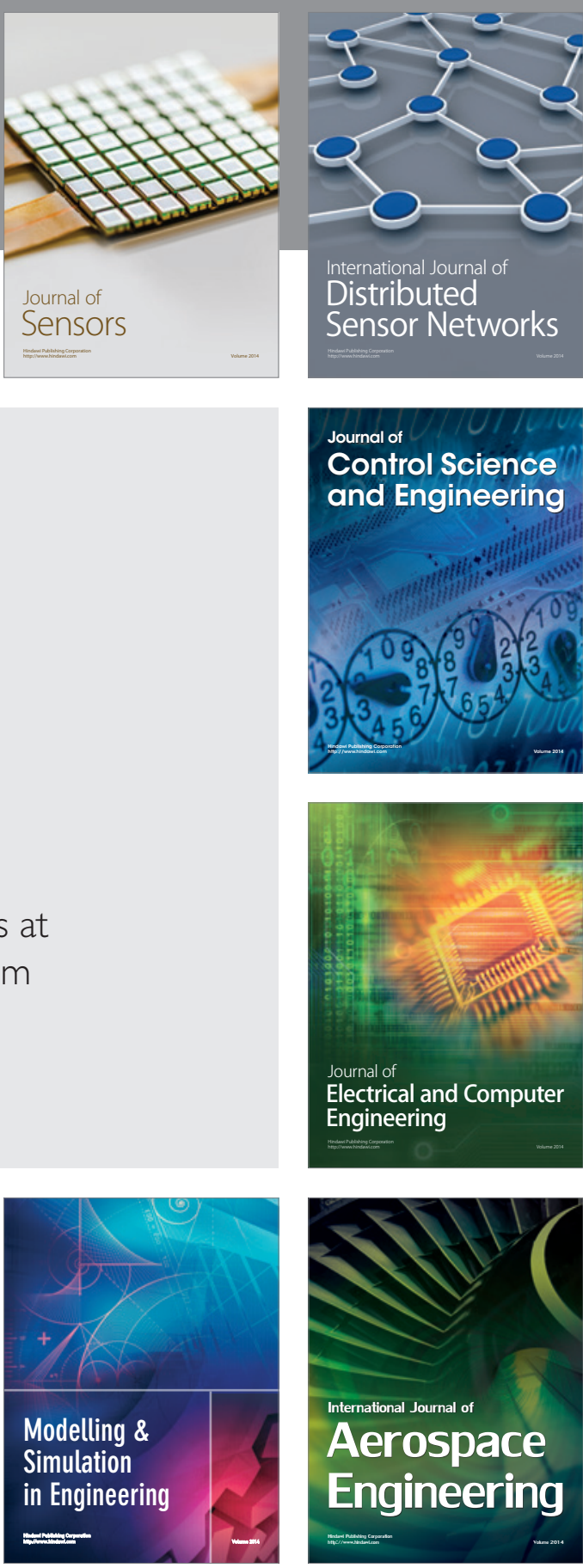

International Journal of

Distributed

Sensor Networks

$-$

Joumal of

Control Science

and Engineering
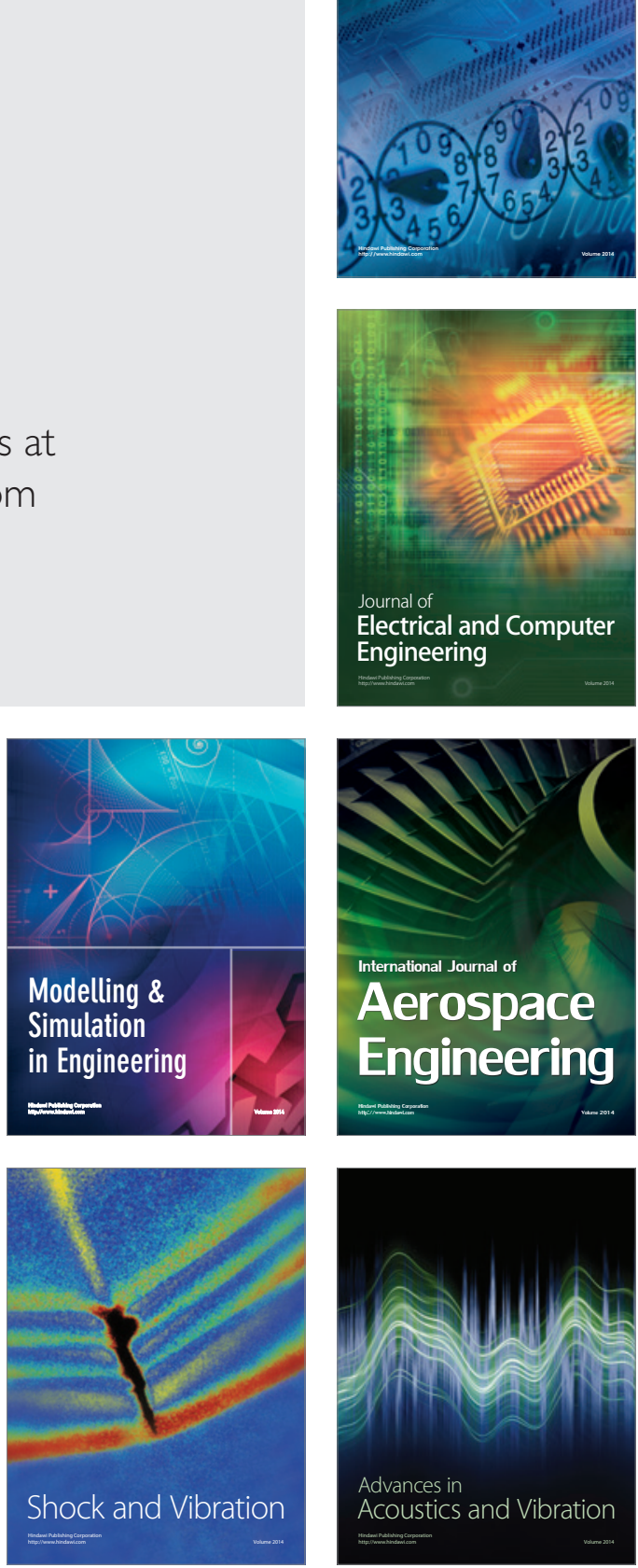